\title{
Peroral endoscopic myotomy as a versatile approach to treating complex esophageal disorders
}

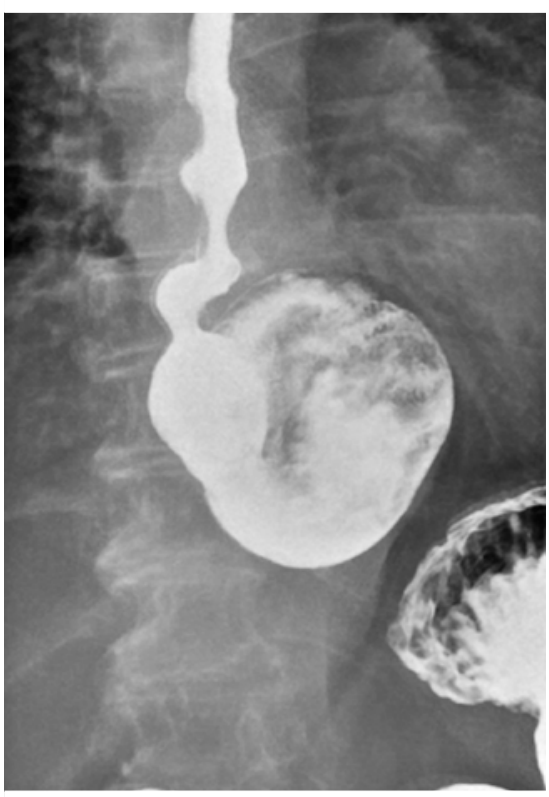

- Fig. 1 Barium study showing a large distal esophageal diverticulum and multiple tertiary contractions, suggesting the diagnosis of Jackhammer esophagus.

Since 2008, peroral endoscopic myotomy (POEM) has evolved as a technique for managing esophageal achalasia [1]. POEM has also recently emerged as a potential therapeutic tool in treating other esophageal motility disorders [2,3], including Jackhammer esophagus and Zenker's diverticulum [4]. However, for mid or lower esophageal diverticulum, the surgical treatment is still recommended, despite being associated with high morbidity. In this video case we report the application of the POEM technique as a therapeutic approach in a patient affected by Jackhammer esophagus, distal esophageal spasm, and a large distal esophageal diverticulum ( $\triangleright$ Fig. 1, $>$ Fig. 2 a).

The aim of this POEM variation was to create a submucosal tunnel as a single access both to the diverticular septum, to perform septotomy, and to the esophageal wall muscle and lower esophageal sphincter (LES), in order to perform myotomy ( $\bullet$ Fig. 3, $\triangleright$ Video 1 ).

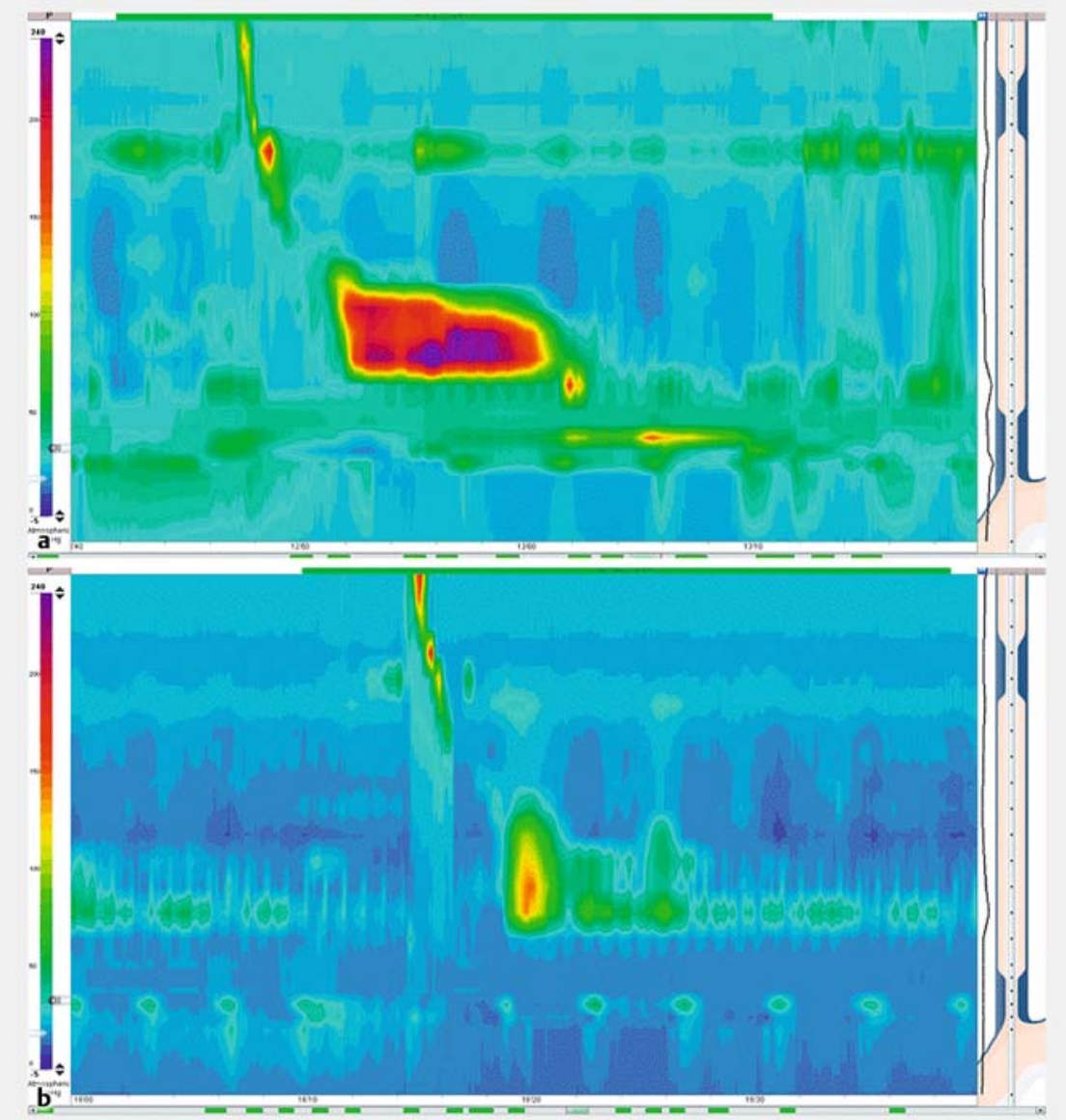

- Fig. 2 High resolution manometry. a Before treatment. Confirmed diagnosis of Jackhammer esophagus and distal esophageal spasm ( $50 \%$ premature contractions; $60 \%$ high amplitude contractions; distal contractile integral $8051 \mathrm{mmHg} . \mathrm{s.cm}$; lower esophageal sphincter (LES) pressure $11 \mathrm{mmHg}$; integrated relaxation pressure $4 \mathrm{~s}: 5 \mathrm{mmHg} . \mathrm{s.cm} ; 4 \mathrm{~cm}$ hiatal hernia). b 1 month follow-up after treatment, showing a significant improvement in the esophageal wall muscle and LES contractility (0\% premature contractions; $20 \%$ high amplitude contractions; distal contractile integral $4616 \mathrm{mmHg} . \mathrm{s.cm}$; LES pressure $4 \mathrm{mmHg}$; integrated relaxation pressure $4 \mathrm{~s}: 1 \mathrm{mmHg}$ ).

Compared with the classical POEM procedure, five phases were defined. After mucosa incision and submucosal tunneling, the myotomy was performed as a hybrid technique. Initially, an anterograde section of the esophageal wall muscle was dissected, starting from the fibers below the diverticular septum, progressing downstream, and ending in the stomach, beyond the LES section. Next, a retrograde septotomy was per- formed, beginning from the most distal septal fibers and working toward the proximal ones. At the end, the tunnel entry was sealed using hemostatic clips. This case report shows that POEM is ver-

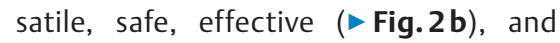
minimally invasive. Its evaluation as a therapeutic tool in patients having mid or distal esophageal symptomatic diverticulum, whether associated with motility disorders or not, should be encour- 


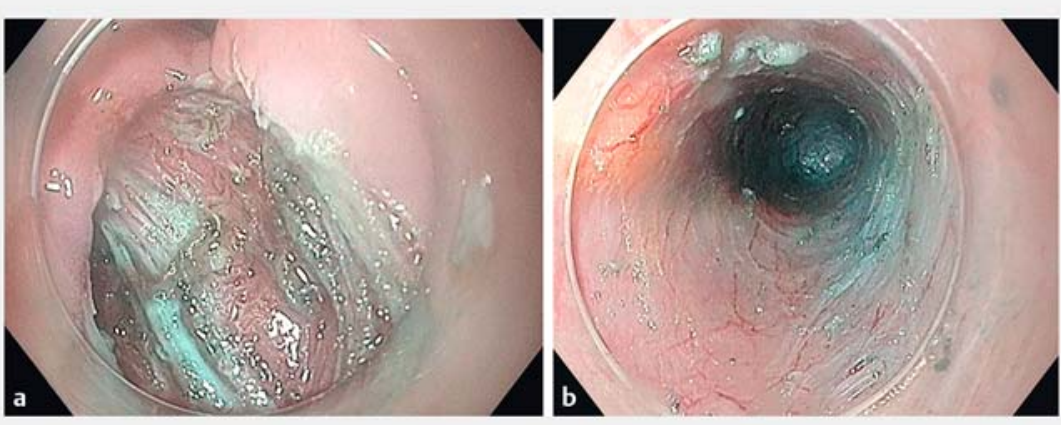

Fig. 3 Endoscopic images. a Anatomical relation between the septal fibers and the mucosa flaps at the tunnel entrance. b Submucosal tunnel.

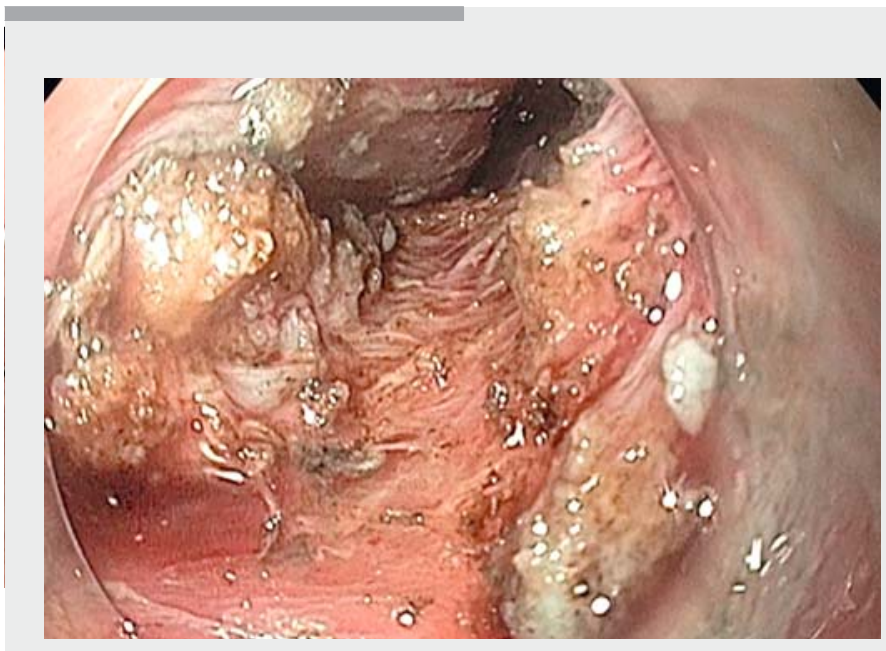

$\checkmark$ Video 1 A modified peroral endoscopic myotomy technique as a therapeutic approach for treating, with a single submucosal tunnel, a complex case combining Jackhammer esophagus, distal esophageal spasm, and a large distal esophageal diverticulum. aged. However, despite the low rate of overall morbidity and mortality reported for conventional POEM [5], it should be carefully customized to each specific case, in order to reduce the risks of potential complications.

Endoscopy_UCTN_Code_TTT_1AO_2AN

\section{Competing interests}

Marc Barthet receives research grant from Boston Scientific. Guido Costamagna receives research grants from Boston Scientific, CooK Endoscopy and Olympus. No further conflicts of interest to disclose.

The authors

Antonella Putignano ${ }^{1}$, Marc Barthet ${ }^{2}$, Ricardo Rio-Tinto ${ }^{3}$, Guido Costamagna ${ }^{4}$, Hubert Louis ${ }^{1}$, Vincent Huberty ${ }^{1}$, Arnaud Lemmers', Jacques Devière ${ }^{1}$

1 Department of Gastroenterology and Hepatopancreatology, Erasme University Hospital, Université Libre de Bruxelles, Brussels, Belgium

2 Department of Gastroenterology, Hôpital Nord, Aix Marseille Université, Marseille, France

3 Digestive Diseases Unit, Champalimaud Clinical Centre, Lisbon, Portugal

4 Digestive Endoscopy Unit, Fondazione Policlinico Universitario A. Gemelli, IRCCS, Rome, Italy

\section{Corresponding author}

\section{Antonella Putignano, MD}

Department of Gastroenterology, Hepatopancreatology, and Digestive Oncology, Erasme Hospital, 808, route de Lennik, Bruxelles 1070, Belgium Fax: +32-2-5554697

antonella.putignano@erasme.ulb.ac.be 


\section{Acknowledgment}

We would like to thank all the professionals who helped to realise this video during the 35th edition of the Gastroenterology and Endotherapy European Workshop (GEEW, Brussels 2017).

\section{References}

[1] Inoue H, Minami H, Kobayashi Y et al. Peroral endoscopic myotomy (POEM) for esophageal achalasia. Endoscopy 2010; 42: 265 271

[2] Mu D, Li YY, Zhang MM et al. POEM for special patient cohorts: a review. J Dig Dis 2017; 18: $265-272$

[3] Louis H, Covas A, Coppens E et al. Distal esophageal spasm treated by peroral endo- scopic myotomy. Am J Gastroenterol 2012; 107: $1926-1927$

[4] Li QL, Chen WF, Zhang XC et al. Submucosal tunneling endoscopic septum division: a novel technique for treating Zenker's diverticulum. Gastroenterology 2016; 151: $1071-1074$

[5] Bechara R, Ikeda H, Inoue H. Peroral endoscopic myotomy: an evolving treatment for achalasia. Nat Rev Gastroenterol Hepatol 2015; 12: 410-426

\section{Bibliography}

DOI https://doi.org/10.1055/a-0600-9529

Published online: 9.5.2018

Endoscopy 2018; 50: E172-E174

(c) Georg Thieme Verlag KG

Stuttgart · New York

ISSN 0013-726X

\section{ENDOSCOPY E-VIDEOS}

https:/|eref.thieme.de/e-videos

回局 Endoscopy E-Videos is a free access online section, reporting 回: on interesting cases and new techniques in gastroenterological endoscopy. All papers include a high quality video and all contributions are freely accessible online.

This section has its own submission website at

https://mc.manuscriptcentral.com/e-videos 